\title{
Evaluation of bacterial hosts for conversion of lignin-derived $p$-coumaric acid to 4-vinylphenol
}

\author{
Alberto Rodriguez ${ }^{1,2}$, Jamie A. Meadows ${ }^{2}$, Ning Sun ${ }^{3}$, Blake A. Simmons ${ }^{1,3}$ and John M. Gladden ${ }^{1,2^{*}}$ (1)
}

\begin{abstract}
Hydroxycinnamic acids such as $p$-coumaric acid (CA) are chemically linked to lignin in grassy biomass with fairly labile ester bonds and therefore represent a straightforward opportunity to extract and valorize lignin components. In this work, we investigated the enzymatic conversion of CA extracted from lignocellulose to 4-vinylphenol (4VP) by expressing a microbial phenolic acid decarboxylase in Corynebacterium glutamicum, Escherichia coli, and Bacillus subtilis. The performance of the recombinant strains was evaluated in response to the substrate concentration in rich medium or a lignin liquor and the addition of an organic overlay to perform a continuous product extraction in batch cultures. We found that using undecanol as an overlay enhanced the 4VP titers under high substrate concentrations, while extracting $>97 \%$ of the product from the aqueous phase. C. glutamicum showed the highest tolerance to CA and resulted in the accumulation of up to $187 \mathrm{~g} / \mathrm{L}$ of 4VP from pure CA in the overlay with a $90 \%$ yield when using rich media, or $17 \mathrm{~g} / \mathrm{L}$ of $4 \mathrm{VP}$ with a $73 \%$ yield from CA extracted from lignin. These results indicate that C. glutamicum is a suitable host for the high-level production of 4VP and that further bioprocess engineering strategies should be explored to optimize the production, extraction, and purification of 4VP from lignin with this organism.
\end{abstract}

Keywords: 4-vinylphenol, Coumaric acid, 4-hydroxystyrene, Microbial conversion, Lignin

\section{Background}

The discovery of sustainable and affordable routes for the production of commodity and specialty biochemicals from renewable sources is essential to reduce the global demand for petroleum and other fossil materials. Lignocellulosic biomass comprises one of the largest reservoirs of renewable carbon in the planet and represents an attractive source of chemical building blocks that can be refined and upgraded into biofuels and bioproducts $([14,15])$. Among the main constituents of lignocellulosic biomass, cellulose and hemicellulose are polymeric carbohydrates that can be deconstructed to monomeric sugars and converted to biofuels and other

\footnotetext{
*Correspondence: jmgladden@lbl.gov

1 Joint BioEnergy Institute, 5885 Hollis St, Emeryville, CA 94608, USA

Full list of author information is available at the end of the article
}

valuable bioproducts [4]. The third main component is lignin, an aromatic heteropolymer with high chemical complexity that makes it more resistant to deconstruction and conversion [30]. Considering that this complexity also opens the possibility to valorize a wide array of aromatic compounds, efforts to depolymerize lignin and chemically or biologically upgrade lignin monomers have steadily increased over the last decade [2, 23, 29]. For example, hydroxycinnamic acids such as $p$-coumaric (CA) and ferulic (FA) acids are precursors of lignin biosynthesis in plants and are chemically linked to lignin grassy biomass at considerable levels $(5-15 \%$ wt.) $[20,26]$. These types of compounds could represent a viable option for valorization of aromatic compounds derived from lignocellulosic feedstocks because they can be extracted through mild thermochemical treatments, are fully metabolized by certain original author(s) and the source, provide a link to the Creative Commons licence, and indicate if changes were made. The images or other third party material in this article are included in the article's Creative Commons licence, unless indicated otherwise in a credit line to the material. If material is not included in the article's Creative Commons licence and your intended use is not permitted by statutory regulation or exceeds the permitted use, you will need to obtain permission directly from the copyright holder. To view a copy of this licence, visit http://creativecommons.org/licenses/by/4.0/. The Creative Commons Public Domain Dedication waiver (http://creativeco mmons.org/publicdomain/zero/1.0/) applies to the data made available in this article, unless otherwise stated in a credit line to the data. 
fungal and bacterial species, and their relative amounts could be increased through bioengineering of crops $[14,15,21,24]$. In particular, CA and FA can be decarboxylated to their vinylphenol derivatives, which hold a high market value due to their applications as biopolymer precursors, perfumes, and food additives.

Several groups have explored the feasibility of using enzymatic approaches to convert CA to 4-vinylphenol (4VP) or FA to 4-vinylguaiacol (4VG) through a single reaction catalyzed by a phenolic acid decarboxylase (PAD) enzyme $[5,8,10,16,16,17,17]$. Over 100 bacterial species are predicted to contain genes coding for PAD enzymes but the best characterized enzymes to date belong to members of the Bacillus and Lactobacillus genera [18]. In addition to using organisms with the natural ability to decarboxylate CA or FA, several PAD enzymes have been heterologously expressed in E. coli and either purified for in vitro reactions or the recombinant strains used in whole-cell conversion methods $[1,10,25]$. However, 4VP has proven to be significantly more toxic to E. coli than CA and there are reports of product inhibition in PAD enzymes [12]. Some strategies that have been employed to mitigate this problem include the use of biphasic systems with an organic overlay, extractive fermentation, and fedbatch approaches. In particular, hexane and octanol are two organic solvents that have proven to be effective at extracting $4 \mathrm{VP}$ from the aqueous phase but are also known to cause significant toxicity to E. coli and inhibition of PAD enzyme activity $[10,16,17,25]$.

Although some organisms, such as Pseudomonas putida and Streptomyces mobaraense, have been used for the production of 4VP from glucose [7, 27] or grass lignin feedstocks [28], the production of 4VP from CA has been attempted primarily in E. coli. Here we explored whether other bacterial species could be more tolerant to higher, more industrially relevant concentrations of substrate and product and to the presence of an organic overlay for product extraction. To do so, the PAD gene from Bacillus amyloliquefaciens was heterologously expressed in Corynebacterium glutamicum, Bacillus subtilis, and E. coli, and their 4VP production capabilities were determined using high-substrate batch cultivations. In an attempt to reduce the toxicity of the overlay, the performance of longer chain fatty alcohols, such as decanol and undecanol, was compared to the more commonly used overlay, octanol. Finally, liquors containing CA extracted from a lignin-rich fraction of lignocellulose were generated through an alkaline treatment and the strains were tested for 4VP production. The 4VP yields and titers obtained under these conditions were compared to those obtained from pure CA in rich medium.

\section{Results and discussion}

\section{Initial characterization of strains}

Three bacterial species were selected in this study for overexpression of a PAD enzyme: E. coli (Ec), B. subtilis (Bs) and C. glutamicum (Cg). Their ability to convert $\mathrm{CA}$ to $4 \mathrm{VP}$ was evaluated and compared to the species carrying the native gene, B. amyloliquefaciens (Ba). These organisms were chosen because they are common protein expression hosts with multiple engineering tools available and do not consume CA or 4VP, with the exception of $\mathrm{Cg}$ that is capable of assimilating CA. The metabolic pathway for assimilation of CA and other phenylpropanoids in C. glutamicum has been described in detail by Kallscheuer et al., and interested readers are encouraged to consult that reference [11]. In an attempt to maximize CA conversion to $4 \mathrm{VP}$ in $\mathrm{Cg}$, a clean deletion of $p h d A$ (coding for an acyl:CoA ligase required for CA degradation) was made to generate a strain unable to metabolize CA (Cg phdA-). It is also worth noting that wild-type Bs harbors a gene coding for a PAD enzyme in its genome; however, a plasmid-based expression is expected to have a positive effect on product formation rates and titers. The PAD from $\mathrm{Ba}$ was selected in this work to be overexpressed in all organisms based on a previous study that identified it as having high specific activity [10]. However, the purpose of this work was not to study the performance of this particular enzyme but rather to determine if organisms such as $\mathrm{Cg}$ and Bs can be efficient $4 \mathrm{VP}$ producers.

The Ec, $\mathrm{Cg}$ and $\mathrm{Cg}$ phdA- strains were transformed with plasmids containing codon-optimized versions of the Ba PAD under the control of the strong IPTGinducible promoter Ptac, called PJAM88 and pJAM89 (Table 1). These strains were named Ec PAD, Cg PAD and $\mathrm{Cg}$ phdA- PAD. Bs was transformed with a similar IPTG-inducible plasmid pJAM90 containing a codonoptimized version of the Ba PAD gene controlled by the strong promoter Pgrac [19], resulting in strain Bs PAD.

To test whether the PAD strains were able to convert $\mathrm{CA}$ to $4 \mathrm{VP}$ and evaluate their tolerance to different concentrations of substrate and product, growth experiments were performed in tryptic soy broth supplemented with 0.25 or $0.5 \mathrm{~g} / \mathrm{L}$ of $4 \mathrm{VP}$, or 1,5 or $10 \mathrm{~g} / \mathrm{L}$ of CA. This rich medium was used to provide all the organisms with glucose and amino acids for growth and cell maintenance and allow for continuous PAD protein production during the 4VP production process. The bacterial cell density was measured at the time of inoculation and after $24 \mathrm{~h}$ of incubation, and PAD expression was induced at the beginning of the cultivations.

The results show that $4 \mathrm{VP}$ is very toxic to all tested organisms, although Ec appeared to be the most sensitive, displaying growth inhibition at concentrations as 
Table 1 Strains and plasmids used in this work. The materials generated in this work are stored at the Joint BioEnergy Institute (JBEI) and can be accessed at https://public-registry.jbei.org with the registry ID numbers provided

\begin{tabular}{|c|c|c|c|}
\hline Strain name & Genotype or description & Source & JBEI Registry ID \\
\hline $\mathrm{Cg}$ & Corynebacterium glutamicum ATCC 13,032 & ATCC & \\
\hline $\mathrm{Cg} \triangle p h d A$ & Corynebacterium glutamicum $\triangle p h d A$ & This study & JPUB_018349 \\
\hline Cg PAD & Corynebacterium glutamicum wild type with pJAM89 & This study & JPUB_018350 \\
\hline $\mathrm{Cg} \triangle p h d A \mathrm{PAD}$ & Corynebacterium glutamicum $\triangle p h d A$ with pJAM89 & This study & JPUB_018352 \\
\hline Bs & Bacillus subtilis RIK1285 (strain 168 derivative) & TakaraBio & \\
\hline Bs PAD & Bacillus subtilis RIK1285 with pJAM90 & This study & JPUB_018354 \\
\hline $\mathrm{Ba}$ & Bacillus amyloliquefaciens ATCC 23,350 & ATCC & \\
\hline Ec & Escherichia coli DH5a & Zymo Research & \\
\hline EC PAD & Escherichia coli DH5a with pJAM88 & This study & JPUB_018346 \\
\hline Plasmid name & Description & Source & JBEI Registry ID \\
\hline pK18mobsacB & suicide vector & ATCC & \\
\hline pZ8-Ptac & IPTG-inducible strong promoter expression vector & $\begin{array}{l}\text { Addgene } \\
\text { [6] }\end{array}$ & \\
\hline pHT08 & IPTG-inducible strong promoter expression vector & MoBiTec & \\
\hline pJAM88 & pZ8-Ptac with PAD codon-optimized for E. coli & This study & JPUB_018347 \\
\hline pJAM89 & pZ8-Ptac with PAD codon-optimized for C. glutamicum & This study & JPUB_018351 \\
\hline pJAM90 & pHT-08 with PAD codon-optimized for B. subtilis & This study & JPUB_018355 \\
\hline
\end{tabular}

low as $0.25 \mathrm{~g} / \mathrm{L}$ (Fig. 1c, f). This agrees with previously reported $4 \mathrm{VP}$ toxicity values for other $E$. coli strains [12]. Cg and Cg phdA-strains showed the highest tolerance to CA by being able to grow in the presence of up to $10 \mathrm{~g} / \mathrm{L}$ of this compound (Fig. 1a, b), while all Bacillus species were unable to grow in media containing more than $1 \mathrm{~g} / \mathrm{L}$ of CA (Fig. $1 \mathrm{~g}-\mathrm{i}$ ).

Notably, the transformed $\mathrm{Cg}, \mathrm{Cg}$ phdA-, and Ec cells exhibited increased sensitivity to CA compared to the non-transformed variants, suggesting that $4 \mathrm{VP}$ formation (and indirectly the initial CA concentration) is causing growth inhibition as a result of PAD expression. We confirmed that $4 \mathrm{VP}$ was produced by all strains that harbor a PAD in media containing CA (Fig. 1). As expected, Bs and Ba can naturally produce 4VP but not the untransformed $\mathrm{Cg}$ or Ec strains. Interestingly, Bs and Ba wild-type strains produced similar 4VP amounts as the transformed strains in this experiment, even when the cell density in the cultures did not increase. Product concentrations reached a plateau around $2.5 \mathrm{~g} / \mathrm{L}$ despite increasing the initial CA concentration from 5 to $10 \mathrm{~g} / \mathrm{L}$. These observations indicate that even a small amount of PAD enzyme (cell densities as low as $0.1 \mathrm{OD}$ ) may be enough to reach inhibitory product concentrations and that $4 \mathrm{VP}$ toxicity (and not substrate availability) is likely limiting the product titers under these conditions.

\section{Use of an organic overlay and high coumarate concentrations}

Previous reports have found that the microbial production of 4VP can be enhanced by using a biphasic cultivation system. One example is the extraction of $4 \mathrm{VP}$ from the aqueous phase with octanol in a continuous flow-bed reactor containing immobilized $E$. coli cells [10]. Although the partition coefficient for 4VP in a mixture of octanol and water is predicted to be high towards octanol, this solvent is also known to cause significant toxicity to microbes [3]. Therefore, we compared the performance of octanol to other mid-chain fatty alcohols with slightly longer alkane chains, decanol and undecanol, when added as overlays to the cultivation media ( $20 \%$ of the aqueous phase volume). To obtain high product concentrations and identify any limitations to the amount of 4VP that can be extracted with the overlays, the four recombinant strains were incubated in the presence of 25 or $75 \mathrm{~g} / \mathrm{L}$ of CA.

We observed differences in the $4 \mathrm{VP}$ yields and titers obtained with each overlay and organism. For example, Bs showed lower conversion yields and product titers than $\mathrm{Cg}$ or Ec (Fig. 2). We found that undecanol performs as well or better than octanol and decanol in terms of $4 \mathrm{VP}$ yields and titers, and this effect appears stronger when using a higher initial CA concentration. Although the titers and yields obtained with $\mathrm{Cg}$ and $\mathrm{Ec}$ in the 


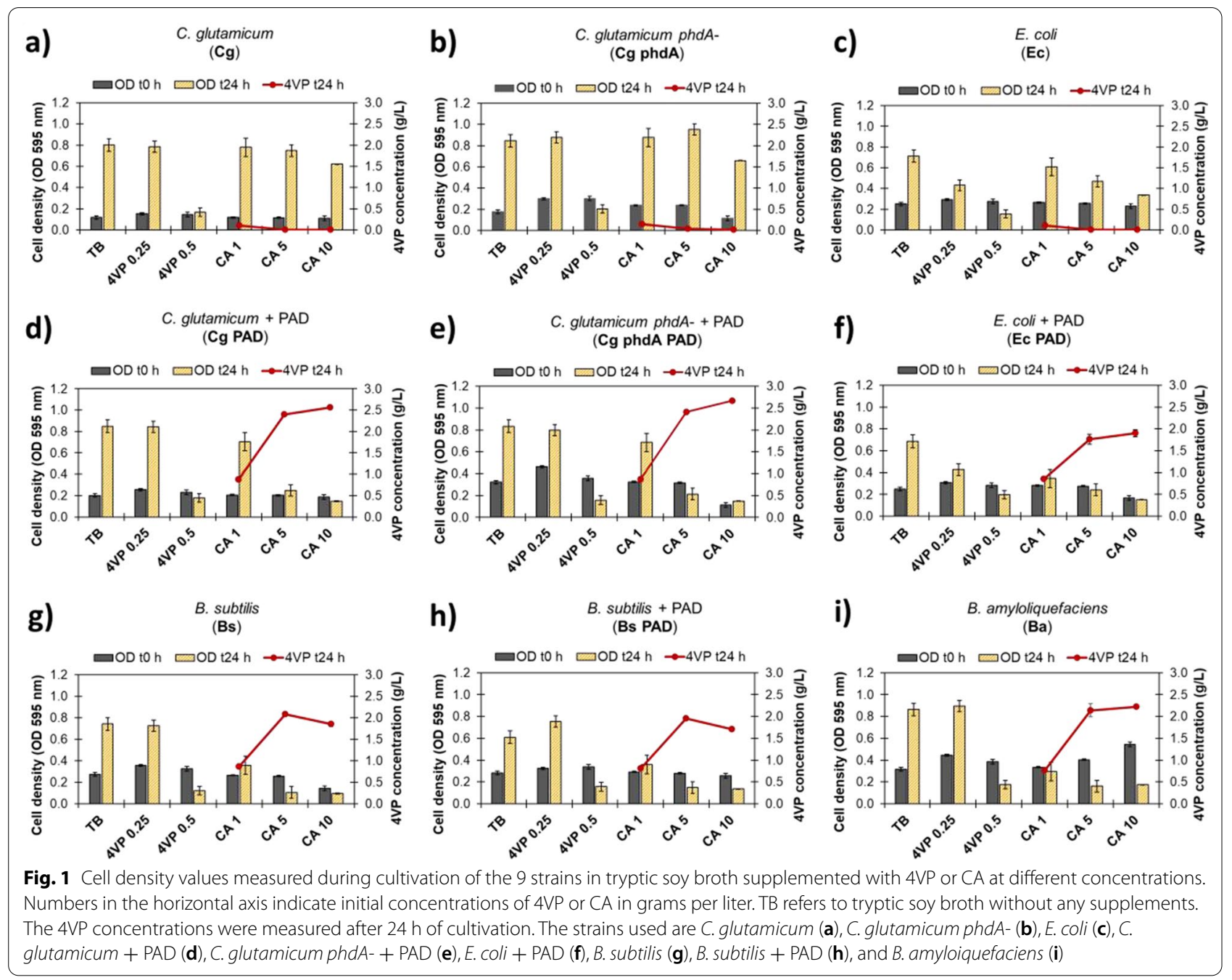

presence of $25 \mathrm{~g} / \mathrm{L}$ of $\mathrm{CA}$ were similar, $\mathrm{Cg}$ performed better in $75 \mathrm{~g} / \mathrm{L}$ of $\mathrm{CA}$, reaching a concentration of $4 \mathrm{VP}$ of $187 \mathrm{~g} / \mathrm{L}$ in the undecanol overlay with a $90 \%$ conversion yield. This could be a consequence of the higher tolerance of this microorganism to $\mathrm{CA}$, as discussed previously. Interestingly, no difference in 4VP production was found between $\mathrm{Cg}$ and $\mathrm{Cg}$ phdA- strains, which suggests that the CA assimilation pathway is not particularly active in the wild-type strain under these conditions.

Remarkably, over $97 \%$ of the 4VP produced was found in the organic phase, while more than $90 \%$ of the CA that was not consumed was found in the aqueous phase. This indicates that the three alcohols are able to efficiently extract and concentrate 4VP from the aqueous phase, while the substrate remains accessible to the cells. The use of an overlay markedly increased the production of 4VP when compared to monophasic cultures (Fig. 1). Undecanol was selected for further experiments based on the results shown in Fig. $2 c, d$ and because it is the mid-chain fatty alcohol with the longest alkane chain that is liquid at room temperature, which could facilitate product recovery from the fermentation broth. It is important to consider that, besides helping cells to produce 4VP for a longer period of time, the inclusion of an overlay also helps to concentrate the product in a smaller volume and may be beneficial for a subsequent purification step.

\section{VP production from lignin-extracted CA}

To explore a renewable source of 4VP production, the strains generated in this work were also tested using CA derived from lignocellulose. The lignin-rich substrate used in this study was derived from a dilute acid pretreatment and enzymatic saccharification of corn stover and is water insoluble. This substrate represents a typical solid waste stream that might be generated in a lignocellulosic biorefinery. To extract $\mathrm{CA}$, the lignin-rich solid residue must be first solubilized under conditions that both 

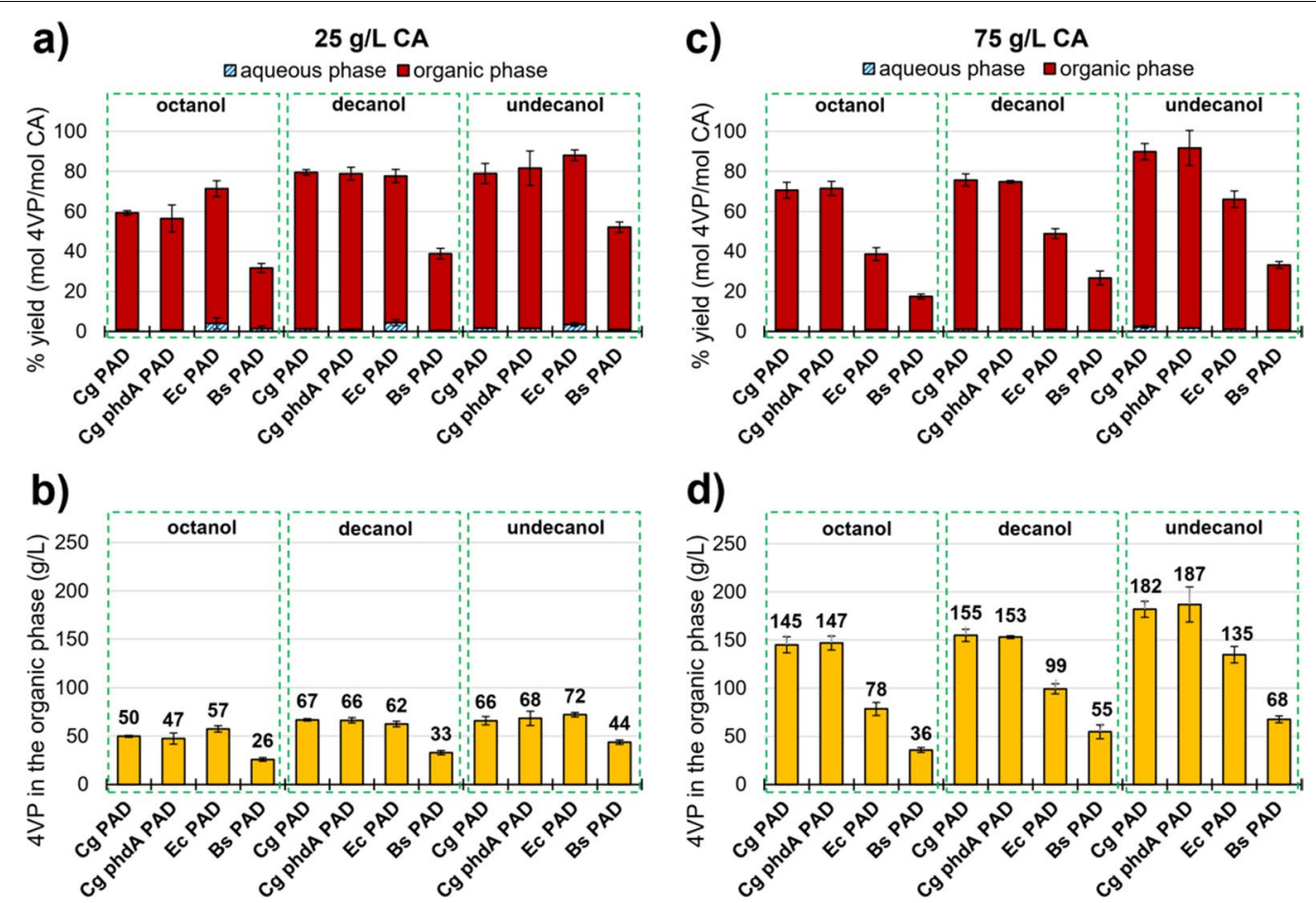

Fig. 2. $4 \mathrm{VP}$ yields $(\mathbf{a}, \mathbf{c})$ and concentrations (b, d) obtained in experiments using tryptic soy broth containing $25 \mathrm{~g} / \mathrm{L}(\mathbf{a}, \mathbf{b})$ or $75 \mathrm{~g} / \mathrm{L}(\mathbf{c}, \mathbf{d})$ of CA. Experiments were inoculated at an OD of 4 and yields were calculated based on the concentrations of 4VP in the aqueous and organic phase relative to the initial CA after $48 \mathrm{~h}$ of cultivation

promote the release of $\mathrm{CA}$ and generate a biocompatible liquor (i.e. having a $\mathrm{pH}$ and salt concentrations within the physiological range of the microbes and low amounts of toxic phenolic compounds). Previous reports indicate that CA yields close to $10 \mathrm{wt} \%$ of the total lignin-rich solids content can be obtained with a base-catalyzed depolymerization method using corn stover lignin [24]. Here, we applied a similar approach to prepare lignin liquors from the water-insoluble residue of corn stover (containing $55 \mathrm{wt} \%$ lignin), obtained after acid pretreatment and saccharification reactions in a pilot-scale process. A relatively high solids load of $25 \%(\mathrm{w} / \mathrm{v})$ was used in the depolymerization reaction to maximize the $\mathrm{CA}$ concentration in solution (Fig. 3). The CA-rich liquor was $\mathrm{pH}$-adjusted to 7.5 and a CA concentration of $8 \mathrm{~g} / \mathrm{L}$ was measured. CA was the main compound detected in HPLC-UV chromatograms obtained from this material (Additional file 1).

The lignocellulose-derived CA was used to cultivate the $4 \mathrm{VP}$ producing strains. The cultivation setup used in the experiment shown in Fig. 2 included the use of multiwell plates and high initial cell densities (as detailed in Methods). This was done to facilitate the screening of all combinations of strains, solvents, and substrate amounts, while minimizing the toxicity imposed by the high CA concentrations. However, this culture system is not amenable for repeated sampling of aqueous and organic phases to quantify metabolites or for monitoring cell growth in the presence of overlays and dark lignin liquors. Therefore, the incubations in CA-rich liquors were performed in culture tubes in presence of an undecanol overlay, and the $\mathrm{OD}, \mathrm{CA}$ and $4 \mathrm{VP}$ concentrations were measured at 0,12 and $24 \mathrm{~h}$ after inoculation. Considering that an organism able to produce $4 \mathrm{VP}$ at a high concentration and yield from lignin should not consume CA as a carbon source and may not necessarily be able to grow on lignin, high initial cell densities (OD 3.5) were also used in this experiment.

Maximum product concentrations were obtained within $12 \mathrm{~h}$ in all cases (Fig. 4). The Ec PAD strain showed the highest product concentration, reaching $21 \mathrm{~g} / \mathrm{L}$ of 4VP with an $88 \%$ yield, followed by strain Cg PAD that produced $17 \mathrm{~g} / \mathrm{L}$ with a $73 \%$ yield (Fig. 4). The Bs PAD strain was once again the lowest $4 \mathrm{VP}$ producer, accumulating only $3 \mathrm{~g} / \mathrm{L}$ of $4 \mathrm{VP}$. Interestingly, the $\mathrm{Cg}$ phdA- PAD strain resulted in low production values under these conditions $(6 \mathrm{~g} / \mathrm{L}$ of $4 \mathrm{VP})$, suggesting that the absence of the acyl:CoA ligase could have adverse consequences for $\mathrm{Cg}$ when cultured in complex lignocellulose-derived media. Overall, the cell densities increased only slightly over the 


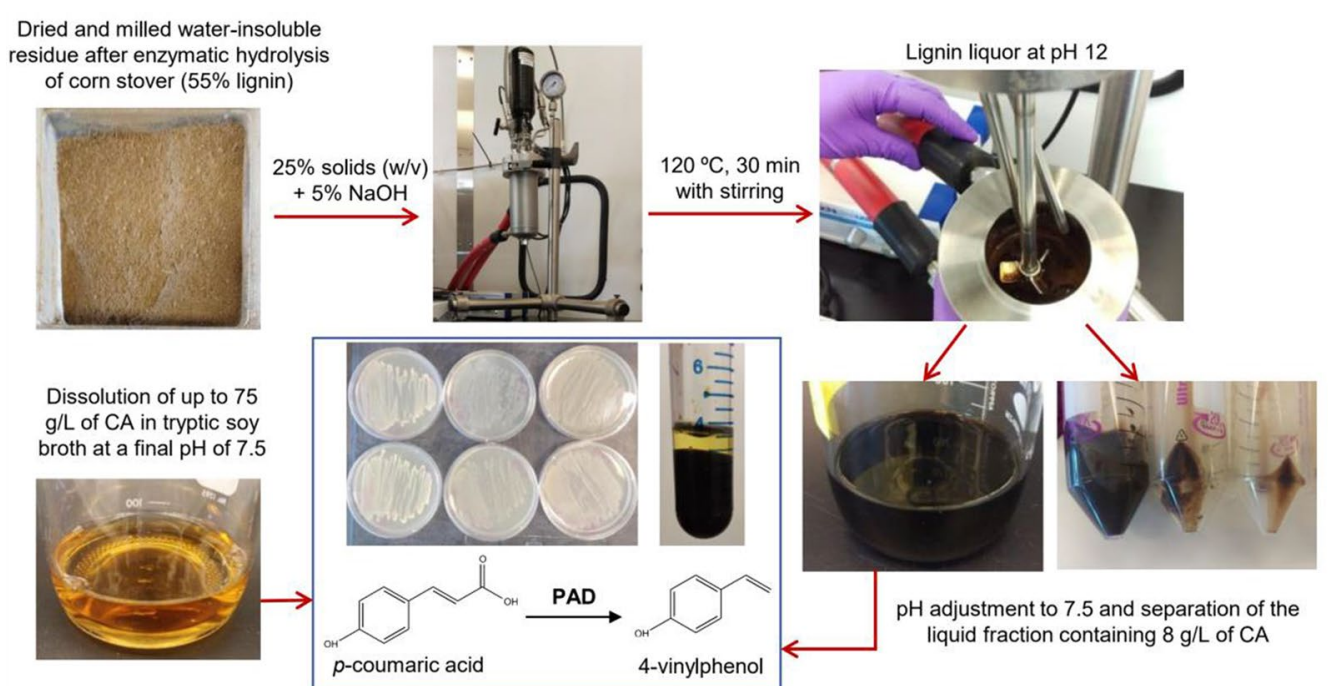

Fig. 3 Scheme of the microbial production of 4-vinylphenol (4VP) from $p$-coumaric acid (CA) in rich media or lignin-derived CA. PAD = phenolic acid decarboxylase

course of the cultivation but no correlation to the $4 \mathrm{VP}$ production values was found.

It is clear that the use of concentrated lignin liquors poses additional challenges to the bioconversion. Besides substrate, product and overlay tolerance, other factors such as the salt concentration and the presence of toxic lignin breakdown products could decrease the efficiency of the process. Therefore, the selection of an organism that can tolerate harsh media conditions and the development of appropriate feeding strategies are critical factors in lignin-derived bioprocesses. The approach described here resulted in an almost complete extraction of the product in the organic phase and higher 4VP concentrations than previously reported when using biological catalysts to produce 4VP from pure CA $[8,10,16,17]$ or lignocellulosic biomass [25].

\section{Conclusions}

This work compared the performance of three organisms in a $4 \mathrm{VP}$ production process and demonstrates its production from CA extracted from a solid ligninrich corn stover bioprocess residue. We found that the plasmid expression of a PAD enzyme in C. glutamicum strains resulted in the highest $4 \mathrm{VP}$ concentrations reported to date in any culture medium. In contrast, $B$. subtilis showed the lowest performance of the recombinant strains in all tested conditions. Continuous extraction of 4VP from the liquid phase with an organic overlay enabled high product concentrations and yields in batch mode, and the best results $(187 \mathrm{~g} / \mathrm{L}$ of $4 \mathrm{VP}$ from pure $\mathrm{CA}$ in the overlay with a $90 \%$ yield) were obtained when using undecanol. The use of undecanol also has the added benefit of enabling recovery of pure $4 \mathrm{VP}$ via a simple vacuum distillation due to the $>40{ }^{\circ} \mathrm{C}$ difference in boiling points between 4 VP $\left(189-206{ }^{\circ} \mathrm{C}\right)$ and undecanol $\left(243{ }^{\circ} \mathrm{C}\right)$. Our results showcase E. coli as the top performing organism in the lignin liquors, C. glutamicum as a promising new host for the high-level production of $4 \mathrm{VP}$, and also indicate that the implementation of an extractive fermentation process could be beneficial to increase the conversion and recovery at higher scales. Overall, the combination of $4 \mathrm{VP}$ conversion host and extractive overlay described in his study outline a process that has a clear route to industrialization for this bioplastic monomer.

\section{Methods}

\section{Chemicals and media}

$p$-coumaric acid, dodecane, octanol, decanol, undecanol, diethyl ether, and all components of M9 medium were purchased from Sigma Aldrich. A 10\% 4-vinylphenol solution in propylene glycol was purchased from Alfa Aesar. Tryptic Soy Broth was purchased from BD Difco and prepared according to the manufacturer's instructions. Coumaric acid (98\%) powder was added to tryptic soy broth at $50^{\circ} \mathrm{C}$ and solubilized by the slow addition of $10 \mathrm{~N} \mathrm{NaOH}$ until the pH was approximately 7.5 , then the medium was filter-sterilized using a $0.45 \mu \mathrm{m}$ surfactantfree cellulose acetate membrane. M9 medium contained the following components (per liter): $6.78 \mathrm{~g}$ of $\mathrm{Na}_{2} \mathrm{HPO}_{4}$, $3 \mathrm{~g}$ of $\mathrm{KH}_{2} \mathrm{PO}_{4}, 0.5 \mathrm{~g}$ of NaCl, $1.98 \mathrm{~g}$ of $\left(\mathrm{NH}_{4}\right) \mathrm{SO}_{4}, 240 \mathrm{mg}$ 


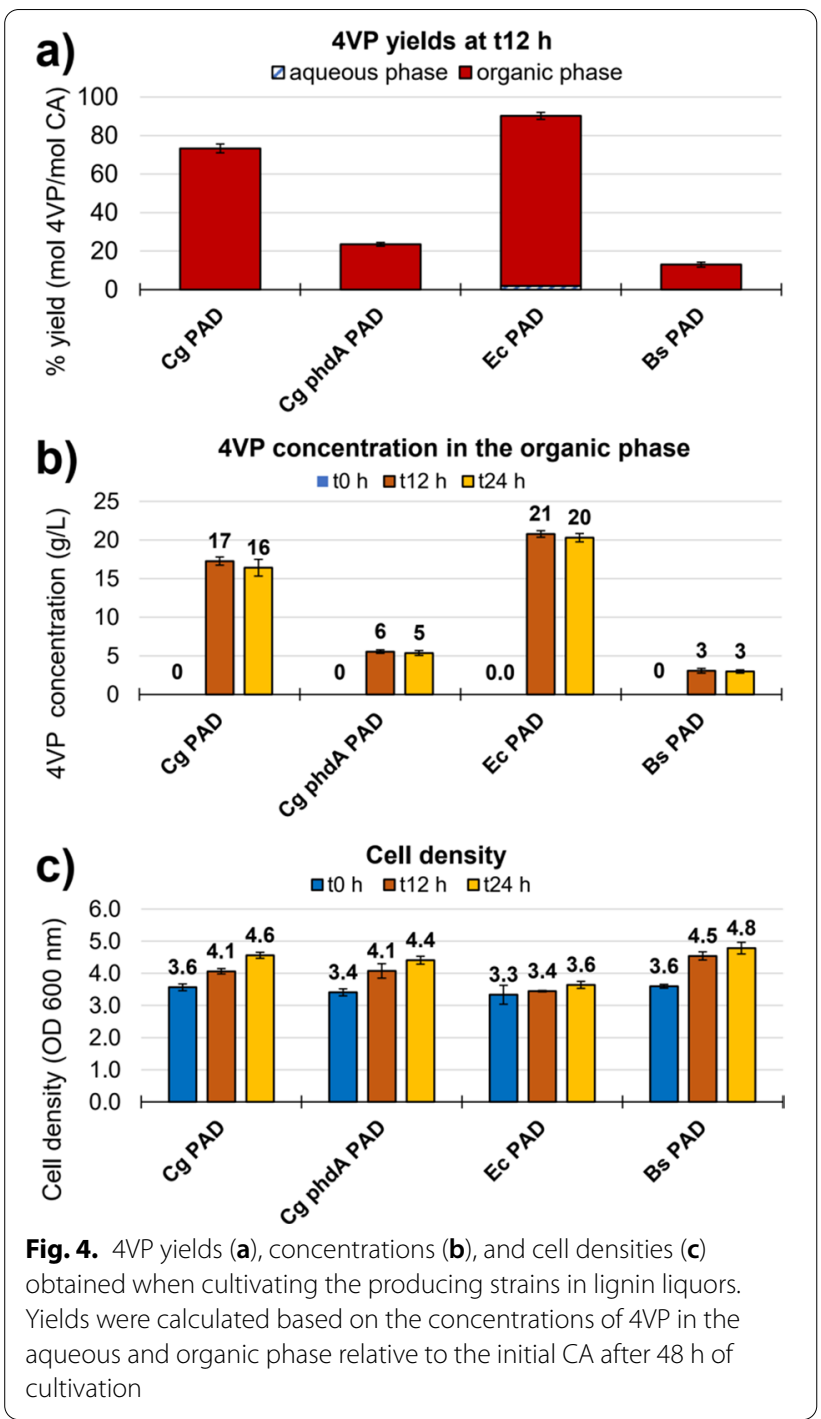

of $\mathrm{MgSO}_{4}, 12 \mathrm{mg}$ of $\mathrm{CaCl}_{2}, 160 \mu \mathrm{g}$ of $\mathrm{CuSO}_{4}, 160 \mu \mathrm{g}$ of $\mathrm{MnSO} 4,160 \mu \mathrm{g}$ of FeSO4, $160 \mu \mathrm{g}$ of $\mathrm{ZnSO} 4,20 \mathrm{mg}$ of thiamine, and $20 \mathrm{mg}$ of biotin. A tenfold concentrated M9 solution was used to supplement lignin liquors in a 1:9 $\mathrm{v} / \mathrm{v}$ ratio to be used as cultivation media for production experiments.

E. coli and B. subtilis were maintained on LB $(10 \mathrm{~g} / \mathrm{L}$ tryptone, $5 \mathrm{~g} / \mathrm{L}$ yeast extract, and $5 \mathrm{~g} / \mathrm{L} \mathrm{NaCl}$ ) plates or liquid and $C$. glutamicum was maintained on LB agar/ liquid or LBHIS agar plates $(5 \mathrm{~g} / \mathrm{L}$ tryptone, $5 \mathrm{~g} / \mathrm{L} \mathrm{NaCl}$, $18.5 \mathrm{~g} / \mathrm{L}$ brain heart infusion, $15 \mathrm{~g}$ agar, and $91 \mathrm{~g} / \mathrm{L}$ sorbitol). C. glutamicum electroporation media are as follows; electrocompetent medium-1: autoclave $1 \mathrm{~g}$ tryptone, 0.5 g yeast extract, $1 \mathrm{~g} \mathrm{NaCl}, 2.5 \mathrm{~g} \mathrm{LB}$ media in $80 \mathrm{~mL}$ water and add filter sterilized $2.5 \mathrm{~g}$ glycine and $50 \mu \mathrm{L}$ tween 80 , in $20 \mathrm{~mL}$ water; and BHIS: $18.5 \mathrm{~g} / \mathrm{L}$ brain heart infusion and $91 \mathrm{~g} / \mathrm{L}$ sorbitol [13].

\section{Plasmid construction}

The gene coding for a phenolic acid decarboxylase (PAD) enzyme in $B$. amyloliquefaciens was codon-optimized for B. subtilis, C. glutamicum, and E. coli, and synthesized by Genscript (Piscataway, NJ, USA). The B. subtilis PAD gene was then cloned into plasmid pHT08 to generate plasmid pJAM90 $\left(\mathrm{Cm}^{\mathrm{R}}\right)$ via Gibson assembly using the DIVA platform at the Joint BioEnergy Institute. The codon-optimized genes for E. coli and C. glutamicum were cloned into the shuttle plasmid pZ8-Ptac to generate plasmids pJAM89 $\left(\mathrm{Km}^{\mathrm{R}}\right)$ and pJAM88 $\left(\mathrm{Km}^{\mathrm{R}}\right)$, respectively. All vectors allowed for the IPTG-inducible expression of the PAD enzyme.

To generate a clean deletion of phdA in C. glutamicum a deletion construct in a $s a c B$ suicide vector was made. The upstream and downstream regions of phdA (Cgl0284) were PCR amplified using C. glutamicum wild type genomic DNA with the following primers (sequences are shown in parentheses): KOphdA-F1-Eco (GTCgaattcCGATGACAGATGCACCCTGA), KOphdAR1 (actagtgttcagtcgatcgttcgaaAGATCACGTTTGAAG TCA), KOphdA-F2 (ttcgaacgatcgactgaacactagtCAC TTGGAGAACGCAATGA), and KOphdA-R2-HindIII (ATGaagcttGCGTCCGAAGAGGTCGGATA). The splice overlap PCR product, made by amplifying the upstream and downstream PCR product with primers KOphdA-F1-Eco and KOphdA-R2-HindIII, was ligated into zero blunt vector (Invitrogen). It was subsequently cut with EcoRI and HindIII and ligated into the similarly cut pK18mobsacB. The strains and plasmids used in this study are listed in Table 1 and those generated in this work can be accessed at https://public-registry.jbei.org using the part ID numbers provided.

\section{Generation of strains}

The microorganisms used in this work are described in Table 1. A C. glutamicum ATCC 13,032 strain that is unable to metabolize coumaric acid was generated by making a clean deletion of $p h d A$, the gene coding for an acyl-CoA ligase (Cgl0284). This was accomplished by performing double homologous recombination and selection via the $s a c B$ system [9]. To integrate the deletion construct into C. glutamicum via transformation, wild type cells were made electrocompetent as per van der Rest with some variations [22]. C. glutamicum grown on LBHIS plates was inoculated into $10 \mathrm{~mL} \mathrm{LB} 2 \%$ glucose and grown overnight at $200 \mathrm{rpm}$ and $30{ }^{\circ} \mathrm{C}$. The overnight culture was inoculated into $1 \mathrm{~L}$ of electrocompetent medium-1 to an OD600nm of 0.3 and grown at $200 \mathrm{rpm}$ at $18{ }^{\circ} \mathrm{C}$ until an OD600nm of 0.9-1.0. The cells were harvested, washed four times with ice cold $10 \% \mathrm{v} / \mathrm{v}$ glycerol, resuspended in $1 \mathrm{~mL} 10 \% \mathrm{v} / \mathrm{v}$ glycerol, and $150 \mu \mathrm{L}$ aliquots were flash frozen in liquid nitrogen and stored at -80 
${ }^{\circ} \mathrm{C}$ until time of electroporation. The transformation to introduce the $p d h A$ deletion construct was done by thawing the electrocompetent cells on ice and electroporating the cells in a $0.2 \mathrm{~mm}$ electroporation cuvette with $1 \mu \mathrm{g}$ of plasmid using the conditions of $25 \mu \mathrm{F}, 200 \Omega, 3 \mathrm{kV}$, for $5 \mathrm{~ms}$. Cells were resuspended in prewarmed $\left(45^{\circ} \mathrm{C}\right)$ $940 \mu \mathrm{L}$ BHIS and incubated for $9 \mathrm{~min}$ at $45^{\circ} \mathrm{C}$. The cells recovered at $200 \mathrm{rpm}$ at $30^{\circ} \mathrm{C}$ for $5 \mathrm{~h}$ before plating cells onto LBHIS agar supplemented with $30 \mu \mathrm{g} / \mathrm{mL}$ kanamycin and incubated at $30^{\circ} \mathrm{C}$. The mutants were verified by PCR and by the inability to grow in CA as the sole carbon source.

In this study, strains with expression plasmids were generated by electroporation and briefly described here. E. coli DH5 $\alpha$ Mix \& Go competent cells were purchased from Zymo Research and transformed by incubation with $1 \mu \mathrm{g}$ of the plasmid DNA pJAM88 at room temperature for $5 \mathrm{~min}$ before plating on LB medium plates containing $30 \mu \mathrm{g} / \mathrm{mL}$ of kanamycin. B. subtilis RIK1285 cells were purchased from Takara Bio and made competent by harvesting them at the onset of stationary phase, following the instructions described by the supplier. Fresh competent cells were transformed with $2 \mu \mathrm{g}$ of plasmid DNA pJAM90 and plated on LB plates with $10 \mu \mathrm{g} / \mathrm{mL}$ of chloramphenicol. C. glutamicum wild-type and the $\triangle p h d A$ mutant were transformed by electroporation as above with these modifications. Both strains were made electrocompetent, thawed, and gently mixed with 100-200 ng of plasmid DNA (pJAM89), electroporated and allowed to recover for $2 \mathrm{~h}$ at $200 \mathrm{rpm}$ at $30{ }^{\circ} \mathrm{C}$ before plating onto LBHIS with $30 \mu \mathrm{g} / \mathrm{mL}$ kanamycin. Transformants were verified by PCR and enzymatic digestion of the extracted plasmids.

\section{Microbial cultivations}

Cultivations were performed in 48-well flat bottom clear plates (Corning, USA) when an organic overlay was not added, in 48-well FlowerPlates (m2p, Germany) when an overlay was added to rich medium, and in $14 \mathrm{~mL}$ roundbottom plastic tubes for lignin liquors with an overlay. Seed cultures of all strains listed in Table 1 were started by inoculating cells from agar plates into tubes with $5 \mathrm{~mL}$ of tryptic soy broth and incubating at $30{ }^{\circ} \mathrm{C}$ with vigorous shaking for $12 \mathrm{~h}$. For the experiments in the clear plates, inocula were prepared by mixing $1 \mathrm{~mL}$ of the seed cultures with $9 \mathrm{~mL}$ of fresh tryptic soy broth and incubated for $8 \mathrm{~h}$. IPTG ( $0.5 \mathrm{mM}$ final concentration) was added to the inocula after $6 \mathrm{~h}$ of incubation. Kanamycin $(30 \mu \mathrm{g} / \mathrm{mL})$ or chloramphenicol $(10 \mu \mathrm{g} / \mathrm{mL})$ were added as required for plasmid maintenance. To start the experiments in the clear plates, $15 \mu \mathrm{L}$ of the inocula were combined with $485 \mu \mathrm{L}$ of tryptic soy broth, with or without supplementation of $4 \mathrm{VP}$ or $\mathrm{CA}$, and incubated with the plastic lid on in a shaking platform at $30^{\circ} \mathrm{C}$ and $200 \mathrm{rpm}$. The optical density at $595 \mathrm{~nm}$ was measured using a DTX880 plate reader (Beckton-Coulter, USA).

For the experiments in the FlowerPlates or culture tubes, seed cultures were started in $5 \mathrm{~mL}$ of tryptic soy broth and incubating at $30^{\circ} \mathrm{C}$ with vigorous shaking for $12 \mathrm{~h}$ with the appropriate antibiotics at the concentrations described above. Cells were transferred to $250 \mathrm{~mL}$ flasks containing $50 \mathrm{~mL}$ of tryptic soy broth (at a $1 / 10$ dilution) and incubated at $30^{\circ} \mathrm{C}$ with shaking in the presence of antibiotics. IPTG $(0.5 \mathrm{mM}$ final concentration) was added to the flasks after $6 \mathrm{~h}$ and incubated again for $2 \mathrm{~h}$. Cell densities were measured, and the cells were centrifuged and resuspended in tryptic soy broth with CA or lignin liquors to obtain an initial OD of 4 . IPTG (0.5 $\mathrm{mM}$ final concentration) was added at the beginning of the cultivations with plasmid-harboring strains. For cultivations in FlowerPlates, $800 \mu \mathrm{L}$ of cells in tryptic soy broth media were combined with $200 \mu \mathrm{L}$ of octanol, decanol or undecanol, covered with a gaspermeable sealing foil with a reduced evaporation layer (m2p, Germany), and incubated inside a humiditycontrolled incubator shaker set at $30^{\circ} \mathrm{C}$ and $900 \mathrm{rpm}$. After $48 \mathrm{~h}$, the entire contents of each Flowerplate well were collected in $1.5 \mathrm{~mL}$ tubes and the dodecane layer, supernatant, and cells were separated by centrifugation. For cultivations in culture tubes, $3.2 \mathrm{~mL}$ of cells in lignin liquors were combined with $0.8 \mathrm{~mL}$ of undecanol and incubated at $30{ }^{\circ} \mathrm{C}$ and $200 \mathrm{rpm}$. Samples from the aqueous phase and undecanol phase were collected every $12 \mathrm{~h}$. The cells in the aqueous phase were briefly centrifuged, resuspended in water, and transferred to a 96-well Costar black clear bottom plates (Corning, USA) to measure OD $600 \mathrm{~nm}$ using a SpectraMax m2 (Molecular Devices, USA). Each fraction was kept at $-20^{\circ} \mathrm{C}$ until analysis. All cultivations were performed in triplicate.

\section{Analytical methods}

CA and 4VP were quantified by HPLC in samples taken from the aqueous and organic phases of the cultivations or lignin liquors after diluting with water (aqueous samples) or pure acetonitrile (organic samples). The analysis was performed with an Agilent Technologies 1200 series instrument equipped with an Eclipse Plus Phenyl-hexyl column (250 mm length, $4.6 \mathrm{~mm}$ diameter, $5 \mu \mathrm{m}$ particle size; Agilent Technologies, USA) kept at $50{ }^{\circ} \mathrm{C}$, and using an injection volume of $5 \mu \mathrm{l}$. The mobile phase was composed of $10 \mathrm{mM}$ ammonium acetate in water (solvent A) and $10 \mathrm{mM}$ ammonium acetate in acetonitrile 90\% (solvent B), prepared from a stock solution of $100 \mathrm{mM}$ ammonium acetate and $0.7 \%$ formic acid in water. The 
following mobile phase gradient profile was used: $30 \%$ B (0 min; $0.5 \mathrm{~mL} / \mathrm{min}), 80 \% \mathrm{~B}(12 \mathrm{~min} ; 0.5 \mathrm{~mL} / \mathrm{min})$, $100 \%$ B (12.1 min; $0.5 \mathrm{~mL} / \mathrm{min}), 100 \%$ B (12.6 min; $1 \mathrm{~mL} / \mathrm{min}), 30 \% \mathrm{~B}$ (12.8 $\mathrm{min} ; 1 \mathrm{~mL} / \mathrm{min}), 30 \% \mathrm{~B}$ (15.6 min; $1 \mathrm{~mL} / \mathrm{min})$. A Poroshell $120 \mathrm{EC}-\mathrm{C} 18 \mathrm{col}-$ umn (50 mm length, $3 \mathrm{~mm}$ diameter, $2.7 \mu \mathrm{m}$ particle size; Agilent Technologies, USA) kept at $22{ }^{\circ} \mathrm{C}$ was also employed for high-throughput analysis of samples collected from FlowerPlate cultivations, by using $40 \%(\mathrm{v} / \mathrm{v})$ acetonitrile in water and $0.04 \%$ formic acid as mobile phase. Coumaric acid and 4-vinylphenol were quantified with a UV detector using $310 \mathrm{~nm}$ and $254 \mathrm{~nm}$ wavelengths, respectively. Analyte concentrations were calculated by comparison of the resulting peak areas to calibration curves made with commercial compounds.

\section{Lignin preparation, depolymerization and coumaric acid extraction}

Corn stover was pretreated in a horizontal screw reactor at $175{ }^{\circ} \mathrm{C}$ with $30 \mathrm{~g} \mathrm{H}_{2} \mathrm{SO}_{4} / \mathrm{kg}$ dry biomass, 30\% $(\mathrm{w} / \mathrm{w})$ total solids loading, and a residence time of $8 \mathrm{~min}$ (Shekiro III). The pretreated corn stover was then neutralized with $40 \%$ (w/w) $\mathrm{NaOH}$ to $\mathrm{pH} 5.5$ before loading of the enzymes. Enzymatic saccharification was performed in a $50 \mathrm{~L}$ IKA SPP50 reactor with $15 \%(\mathrm{w} / \mathrm{w})$ solid loading. The total batch mass was $30 \mathrm{~kg}$ with cellulose (CTec2) $64 \mathrm{mg}$ protein/g dry biomass and xylanase (HTec2) $8 \mathrm{mg}$ protein/g dry biomass. After $96 \mathrm{~h}$ incubation, the reaction was stopped, and the slurry was transferred out. Lignin rich solid was separated from the hydrolysate using a basket centrifuge with a polypropylene filter bag (pore size 25-30 micron) as the liner.

The lignin-rich residue obtained after saccharification was washed with water to remove low molecular weight compounds. This material was oven-dried at 50 ${ }^{\circ} \mathrm{C}$ for $48 \mathrm{~h}$, ground with a mortar and pestle and milled using a $2 \mathrm{~mm}$ sieve. Compositional analysis of the dried sample revealed lignin, glucan, and xylan contents of $54.5 \%, 13.7 \%$, and $3.8 \%$, respectively. This sample was subjected to a base-catalyzed depolymerization process, as follows: (1) $37.5 \mathrm{~g}$ of solids were mixed with $150 \mathrm{~mL}$ of $5 \% \mathrm{NaOH}$ in a stainless steel pressure reactor containing an impeller and a jacket for temperature control (Buchiglas, Switzerland); (2) a reaction was carried at $120^{\circ} \mathrm{C}$ and for $30 \mathrm{~min}$ (in addition to a $35 \mathrm{~min}$ heating up and a 25 min heating down ramps); (3) a lignin liquor with a $\mathrm{pH}$ of 12 was recovered and the $\mathrm{pH}$ was adjusted to 7.5 with concentrated $\mathrm{H}_{2} \mathrm{SO}_{4}$; (4) the liquid phase was recovered by centrifugation and filtered through $0.45 \mu \mathrm{m}$ surfactant-free cellulose acetate membranes. The recovered liquor was supplemented with M9 salts (1/10 vol. of a $10 \times$ M9 stock), resulting in a concentration of $8 \mathrm{~g} / \mathrm{L}$ of $\mathrm{CA}$.

\section{Supplementary Information}

The online version contains supplementary material available at https://doi. org/10.1186/s12934-021-01670-8.

Additional file 1. HPLC-UV chromatogram obtained from the lignin liquor at $\mathrm{pH} 7.5$ prepared in this work and used for bioconversion. The sample was diluted 100 -fold in water before analysis.

\section{Authors' contributions}

AR and JMG conceived the idea and designed the experiments. JAM and AR constructed the transformed and mutant strains. NS prepared the lignin-rich material. AR performed microbial conversion experiments and analyzed the results. BAS and JMG supervised the research. All authors read and approved the final manuscript.

\section{Funding}

This work was part of the DOE Joint BioEnergy Institute (http://www.jbei.org) supported by the U.S. Department of Energy, Office of Science, Office of Biological and Environmental Research, through contract DE-AC02-05CH11231 between Lawrence Berkeley National Laboratory and the U.S. Department of Energy. The United States Government retains and the publisher, by accepting the article for publication, acknowledges that the United States Government retains a non-exclusive, paid-up, irrevocable, worldwide license to publish or reproduce the published form of this manuscript, or allow others to do so, for United States Government purposes. The Department of Energy will provide public access to these results of federally sponsored research in accordance with the DOE Public Access Plan (http://energy.gov/downloads/ doe-public- access-plan)

Sandia National Laboratories is a multimission laboratory managed and operated by National Technology \& Engineering Solutions of Sandia, LLC, a wholly owned subsidiary of Honeywell International Inc., for the U.S. Department of Energy's National Nuclear Security Administration under contract DE-NA0003525. This paper describes objective technical results and analysis. Any subjective views or opinions that might be expressed in the paper do not necessarily represent the views of the U.S. Department of Energy or the United States Government.

Availability of data and materials

All data generated and analyzed during this study are included in this article and its additional files.

\section{Declarations}

Ethics approval and consent to participate

Not applicable.

Consent for publication

Not applicable.

\section{Competing interests}

No competing interests to declare.

\section{Author details}

${ }^{1}$ Joint BioEnergy Institute, 5885 Hollis St, Emeryville, CA 94608, USA. ${ }^{2}$ Sandia National Laboratories, 7011 East Ave, Livermore, CA 94551, USA. ${ }^{3}$ Lawrence Berkeley National Laboratory, 1 Cyclotron Rd, Berkeley, CA 94720, USA.

Received: 24 May 2021 Accepted: 30 August 2021

Published online: 15 September 2021 


\section{References}

1. Barthelmebs L, Diviès C, Cavin JF. Expression in Escherichia coli of native and chimeric phenolic acid decarboxylases with modified enzymatic activities and method for screening recombinant $E$. coli strains expressing these enzymes. Appl Environ Microbiol. 2001;67:1063-9.

2. Beckham GT, Johnson CW, Karp EM, Salvachúa D, Vardon DR. Opportunities and challenges in biological lignin valorization. Curr Opin Biotechnol. 2016;42:40-53.

3. Blank LM, Ionidis G, Ebert BE, Bühler B, Schmid A. Metabolic response of Pseudomonas putida during redox biocatalysis in the presence of a second octanol phase. FEBS J. 2008;275:5173-90.

4. Bomble YJ, Lin C-Y, Amore A, Wei H, Holwerda EK, Ciesielski PN, et al. Lignocellulose deconstruction in the biosphere. Curr Opin Chem Biol. 2017:41:61-70.

5. Chen Y, Li L, Long L, Ding S. High cell-density cultivation of phenolic acid decarboxylase-expressing Escherichia coli and 4-vinylguaiacol bioproduction from ferulic acid by whole-cell catalysis. J Chem Technol Biotechnol. 2018;93:2415-21.

6. Cleto S, Jensen JVK, Wendisch VF, Lu TK. Corynebacterium glutamicum metabolic engineering with CRISPR interference (CRISPRi). ACS Synth Biol. 2016:5:375-85.

7. Fujiwara R, Noda S, Kawai Y, Tanaka T, Kondo A. 4-Vinylphenol production from glucose using recombinant Streptomyces mobaraense expressing a tyrosine ammonia lyase from Rhodobacter sphaeroides. Biotechnol Lett. 2016:38:1543-9.

8. Hu H, Li L, Ding S. An organic solvent-tolerant phenolic acid decarboxylase from Bacillus licheniformis for the efficient bioconversion of hydroxycinnamic acids to vinyl phenol derivatives. Appl Microbiol Biotechnol. 2015:99:5071-81.

9. Jäger W, Schäfer A, Pühler A, Labes G, Wohlleben W. Expression of the Bacillus subtilis sacB gene leads to sucrose sensitivity in the gram-positive bacterium Corynebacterium glutamicum but not in Streptomyces lividans. J Bacteriol. 1992;174:5462-5.

10. Jung D-H, Choi W, Choi K-Y, Jung E, Yun H, Kazlauskas RJ, Kim B-G. Bioconversion of $\mathrm{p}$-coumaric acid to $p$-hydroxystyrene using phenolic acid decarboxylase from B. amyloliquefaciens in biphasic reaction system. Appl Microbiol Biotechnol. 2013;97:1501-11.

11. Kallscheuer N, Vogt M, Kappelmann J, Krumbach K, Noack S, Bott M, Marienhagen J. Identification of the phd gene cluster responsible for phenylpropanoid utilization in Corynebacterium glutamicum. Appl Microbiol Biotechnol. 2016;100:1871-81.

12. Licandro-Seraut H, Roussel C, Perpetuini G, Gervais P, Cavin J-F. Sensitivity to vinyl phenol derivatives produced by phenolic acid decarboxylase activity in Escherichia coli and several food-borne Gram-negative species. Appl Microbiol Biotechnol. 2013;97:7853-64.

13. LiebI W, Bayerl A, Schein B, Stillner U, Schleifer KH. High efficiency electroporation of intactCorynebacterium glutamicum cells. FEMS Microbiol Lett. 1989;65:299-303.

14. Liu Y, Nie Y, Lu X, Zhang X, He H, Pan F, et al. Cascade utilization of lignocellulosic biomass to high-value products. Green Chem. 2019;21:3499-535.

15. Liu Z-H, Le RK, Kosa M, Yang B, Yuan J, Ragauskas AJ. Identifying and creating pathways to improve biological lignin valorization. Renew Sustain Energy Rev. 2019;105:349-62.

16. Li L, Long L, Ding S. Bioproduction of high-concentration 4-vinylguaiacol using whole-cell catalysis harboring an organic solvent-tolerant phenolic acid decarboxylase from Bacillus atrophaeus. Front Microbiol. 2019;10:1798.

17. Li L, Wu X, Long L, Ding S. Functional autodisplay of phenolic acid decarboxylase using a GDSL autotransporter on escherichia coli for efficient catalysis of 4-hydroxycinnamic acids to vinylphenol derivatives. Catalysts. 2019;9:634

18. Parada-Fabián JC, Hernández-Sánchez H, Méndez-Tenorio A. Substrate specificity of the phenolic acid decarboxylase from Lactobacillus plantarum and related bacteria analyzed by molecular dynamics and docking. J Plant Biochem Biotechnol. 2018;28:1-14.

19. Phan TTP, Nguyen HD, Schumann W. Novel plasmid-based expression vectors for intra-and extracellular production of recombinant proteins in Bacillus subtilis. Protein Expr Purif. 2006;46:189-95.

20. Ralph J. Hydroxycinnamates in lignification. Phytochem Rev. 2010;9:65-83.

21. Ralph J, Lapierre C, Boerjan W. Lignin structure and its engineering. Curr Opin Biotechnol. 2019;56:240-9.

22. van der Rest ME, Lange C, Molenaar D. A heat shock following electroporation induces highly efficient transformation of Corynebacterium glutamicum with xenogeneic plasmid DNA. Appl Microbiol Biotechnol. 1999;52:541-5

23. Rinaldi R, Jastrzebski R, Clough MT, Ralph J, Kennema M, Bruijnincx PCA, Weckhuysen BM. Paving the way for lignin valorisation: recent advances in bioengineering, biorefining and catalysis. Angew Chem Int Ed Engl. 2016:55:8164-215.

24. Rodriguez A, Salvachúa D, Katahira R, Black BA, Cleveland NS, Reed M, et al. Base-catalyzed depolymerization of solid lignin-rich streams enables microbial conversion. ACS Sustain Chem Eng. 2017;5:8171-80.

25. Salgado JM, Rodríguez-Solana R, Curiel JA, de Las Rivas B, Muñoz R, Domínguez JM. Bioproduction of 4-vinylphenol from corn cob alkaline hydrolyzate in two-phase extractive fermentation using free or immobilized recombinant E. coli expressing pad gene. Enzyme Microb Technol. 2014;58-59:22-8.

26. Sibout R, Le Bris P, Legée F, Cézard L, Renault H, Lapierre C. Structural redesigning arabidopsis lignins into alkali-soluble lignins through the expression of p-coumaroyl-CoA: monolignol transferase PMT. Plant Physiol. 2016;170:1358-66.

27. Verhoef S, Wierckx N, Westerhof RGM, de Winde JH, Ruijssenaars HJ. Bioproduction of p-hydroxystyrene from glucose by the solvent-tolerant bacterium Pseudomonas putida S12 in a two-phase water-decanol fermentation. Appl Environ Microbiol. 2009;75:931-6.

28. Williamson JC, Bahrin N, Hardiman EM, Bugg TDH. Production of substituted styrene bioproducts from lignin and lignocellulose using engineered Pseudomonas putida KT2440. Biotechnol J. 2020;15:1900571.

29. Xu C, Arancon RAD, Labidi J, Luque R. Lignin depolymerisation strategies: towards valuable chemicals and fuels. Chem Soc Rev. 2014;43:7485-500.

30. Yoo CG, Meng X, Pu Y, Ragauskas AJ. The critical role of lignin in lignocellulosic biomass conversion and recent pretreatment strategies: a comprehensive review. Bioresour Technol. 2020:301:122784.

\section{Publisher's Note}

Springer Nature remains neutral with regard to jurisdictional claims in published maps and institutional affiliations.

Ready to submit your research? Choose BMC and benefit from

- fast, convenient online submission

- thorough peer review by experienced researchers in your field

- rapid publication on acceptance

- support for research data, including large and complex data types

- gold Open Access which fosters wider collaboration and increased citations

- maximum visibility for your research: over 100M website views per year

At BMC, research is always in progress.

Learn more biomedcentral.com/submissions 